\title{
A Clínica das Mulheres: \\ Erotomania e Devastação
}

\author{
Fernanda Cabral Samico \\ Universidade Severino Sombra, Centro de Letras, Ciências, \\ Sociais Aplicadas e Humanas, Curso de Psicologia \\ fernandasamico@uss.br
}

\begin{abstract}
Resumo: $O$ discurso das mulheres é marcado por uma condição que não comparece no discurso dos homens: a familiaridade com o $S(\not X)$. Isso marca uma especificidade no discurso das mulheres, em análise, e em seus enlaces amorosos, inclusive os transferenciais, pois perpassam a condição feminina que carregam. Esta especificidade está na maneira com que enlaçam o amor e a questão de sua própria existência. Desde Freud, sabemos que, com a castração há a inscrição de uma falta articulada ao significante, o que leva uma mulher a reeditar seu vínculo pré-edipiano com o Outro primordial, na esperança de obter um significante que a represente como mulher. A insistência desse endereçamento de demanda infinita de amor, Lacan nomeia de devastação. Para as mulheres, amor e devastação possuem estreito parentesco porque ambos estão sob o registro do sem limite e da falta de significante no Outro. Diante da falta de um significante que defina o que é uma mulher, a devastação comparece como resposta no relacionamento entre mãe e filha, nas parcerias amorosas e nas relações transferenciais em análise.
\end{abstract}

Palavras-chave: Psicanálise. Feminino. Devastação. Parceria.

\section{The Clinic for Women:}

\section{Erotomania and Devastation}

\begin{abstract}
The discourse of women is marked by a condition that does not attend the discourse of man: the familiarity with the $S(\mathbb{X})$. This indicates a specifity in women's speech in analysis and their Love links, including the transfer, as embraced by the feminin condition they carry. This specificity is snared in the way that women connect love and the question of their own existance. Since Freud is known that with the castration there is an inscription of a fault articulated with the significant, wich leads a woman to re-edit her link with the pré-Oedipa, primary Other in hopes of getting a signifier that represents her as a woman. Lacan names devastation the insistent adressing of an infinite demand of love. For women, love and devastation are closely related because both are located under the limitless and under lack of significant in the Other. Given the lack of a significant to define what is a woman, the devastation comes to appear as an
\end{abstract}


answer in the relationship between mother and daughter, in loving partnerships and in the transference occured is analysis.

Keywords: Psychoanalysis. Feminin. Devastation. Partnership.

Em 1912, em seu texto técnico "Recomendações aos médicos que exercem Psicanálise", Freud afirma que, na execução da psicanálise, pesquisa e tratamento coincidem. A partir disso, um trabalho de pesquisa em psicanálise deve ter como proposta uma articulação entre a teoria e a clínica. Neste espaço de experiência psicanalítica, o sujeito da pesquisa em psicanálise é o sujeito da linguagem: marcado pela cisão e submetido pelo desejo. No cerne de todo tema que envolve o sujeito e seu desejo, encontramos questões concernentes ao vínculo construído com o Outro primordial e que se reatualiza, tanto nos sintomas, quanto nas relações transferenciais criadas em análise. "A prática da psicanálise”, confirma Brousse, "coloca em evidência um real clínico que se manifesta no retorno insistente ao mesmo lugar" (BROUSSE, 2004). Neste trabalho pretendemos, com a ajuda de vinhetas retiradas da clínica que conduzimos, sustentar a idéia de que há uma especificidade no discurso das mulheres em análise e que seus enlaces amorosos, inclusive os transferenciais, perpassam pela condição feminina que carregam.

\section{A Clínica das Mulheres}

Existe diferença entre a clínica das mulheres e a clínica dos homens? Lacan já afirmara que homens e mulheres são meramente significantes e o que se deve levar em conta, de fato, é a maneira como o falasser, independente de sua configuração anatômica, faz o arranjo de sua escolha identificatória sexual. Mas se consideramos, ainda, que a fantasia fundamental é uma tessitura simbólico-imaginária e que a configuração do Eu se inicia por uma matriz imaginária, como não considerar que a diferença anatômica entre os sexos produzirá efeitos no discurso do sujeito, marcando uma singularidade na maneira que se posicionam em análise?

Ora, o que vemos é que a própria diferença é uma questão. É claro que a fala, nos homens e nas mulheres, é diferente; é diferente pelo estilo, pelo tom, pelo conteúdo. Fala-se como homem ou como mulher, e se fala disso porque existem os significantes (SOLER, 2005)

Soler (2005) ainda ensina que, apesar de a anatomia não ser o destino para a identificação sexual e cada sujeito ter a liberdade de se alinhar de um lado ou do outro das fórmulas quânticas de sexuação, "convém notar que, nessa matéria, não se pode tratar de uma liberdade por indiferença, porque o significante está ligado à anatomia.." (SOLER, 2005) O sujeito já nasce sendo referido por uma teia significante sustentada pela constelação familiar e será, mesmo antes de nascer, representado por um dos significantes: menino ou menina. A escolha sexual, portanto, é uma escolha aconselhada. 
A noção psicanalítica de sexuação e identificação sexual tem um grande avanço quando, entre seus seminários 17 (1969-70) e 19 (1971-72), Lacan começa a esboçar a demonstração lógica de que as categorias masculino e feminino funcionam como campos específicos de gozos. Ensina Roudinesco (1998):

\footnotetext{
"No contexto de sua última reformulação lógica, na qual apareceram as idéias de matema e nó borromeano, Jacques Lacan construiu, em 1973, um matema da identidade sexual, mediante o qual tentou superar o falicismo freudiano e estabelecer sua própria concepção de sexualidade feminina e da diferença sexual." (ROUDINESCO \& PLON, 1998)
}

Com a finalização da criação das fórmulas de sexuação, apresentadas em seu seminário 20 (1972-1973), Lacan apresenta um novo paradigma para a investigação sobre a sexualidade humana. Ele parte da argumentação de que tanto a identidade quanto a partilha sexual nos seres humanos se dão a partir da função fálica, uma vez que homens e mulheres habitam a linguagem, mas não totalmente sob suas regras.

Seguindo este raciocínio, no ser falante, não é a biologia ou a ciência genética que determina o que é um homem ou o que é uma mulher, mas uma posição eleita pelo sujeito falante. "Os homens, as mulheres e as crianças não são mais do que significantes" (LACAN, 1972-1973/1985). Logo, se lermos os enunciados das fórmulas de sexuação, perceberemos que tanto a posição masculina quanto a feminina são indicadores de uma divisão do sujeito e a escolha de uma das posições é efeito da localização do sujeito em um dos campos: o esquerdo, chamado de masculino, ou o direito, chamado de feminino. Em outras palavras, a diferença de posição ou de identificação de sexuação não se institui nos seres falantes pela carga genética, mas serão homens ou mulheres a partir da maneira pela qual se inserem como sujeitos em uma das posições de sexuação.

O que vai apontar a escolha identificatória sexual do sujeito ultrapassa o biológico. Como exemplo, temos miríades de fenômenos que subvertem a ordem biológica, que vão desde os travestis, até sujeitos que são geneticamente reconhecidos como homens, mas se identificam sexualmente como mulheres: os transexuais. "O ser sexuado do organismo (...) não basta para criar o ser sexuado do sujeito" (SOLER, 2005). Muito menos para constituir um saber sobre o sexo.

A criação das fórmulas quânticas de sexuação introduz no campo psicanalítico um novo raciocínio sobre a questão da castração e, portanto, da lógica fálica. Não achamos de relevância, para esse trabalho, explicar de forma detalhada as fórmulas em seus termos lógicos. Daremos destaque às conseqüências das fórmulas para o entendimento da partilha sexual.

Começamos sublinhando a equação do que Lacan chama de lado da posição masculina. Deve haver um para o qual a castração não funciona, enquanto todos os outros estão submetidos à castração. Com referência a isso, Lacan diz:

É apenas da ordem do complemento introduzido acima (aqui se refere ao $\Phi x$ ) em qualquer postulação do universal como tal que, num ponto do discurso, seja preciso que uma existência, como se costuma dizer, oponha-se como 
desmentido à função fálica, para que postulá-la seja "possível”, o que é o pouco com que ela pode pretender à existência (LACAN, 1972/2003).

É abaixo das fórmulas lógicas desse lado do chamado Homem, que Lacan apresenta os símbolos $\$$ e $\Phi$. Os termos são colocados da seguinte forma:

(...) Do lado do homem, inscrevi aqui, não certamente para privilegiá-lo de modo algum, o $\$$ e o $\Phi$ que o suporta como significante, o que bem se encarna também no $\mathrm{S}_{1}$, que é, entre todos os significantes, esse significante do qual não há significado, e que, quanto ao sentido, simboliza seu fracasso (LACAN, 1972-1973/1985).

A consequência de localizar o sujeito barrado e o falo no lado homem é designá-los como suporte da posição masculina, ou seja, o que determina o lado masculino é o falo, representado pelo $\Phi$, que se apresenta também como suporte do sujeito do inconsciente, \$. Uma vez que o ser humano habita o campo da linguagem, o falo é o significante que, enquanto função, simboliza sua entrada no simbólico e também a operação da castração no mesmo. Murta (2006) explica que o fracasso a que Lacan se refere relaciona-se exatamente com a função fálica, pois um sexo não se relaciona com o Outro do sexo que estaria em sua oposição. Essa é mais uma maneira de dizer que não existe relação sexual. Apesar das flechas que cruzam os campos darem uma idéia de que estes se comunicam, Lacan elucida que

(...) esse $\$$ só tem a ver, enquanto parceiro, com o objeto $a$ inscrito do outro lado da barra. Só lhe é dado atingir seu parceiro sexual, que é o Outro, por intermédio disto, de ele ser a causa de seu desejo. A este título, como o indica alhures em meus gráficos, a conjunção apontada desse $\$$ e desse $\boldsymbol{a}$, isto não é outra coisa senão fantasia (LACAN, 1972-1973/1985).

Portanto, é somente pela via da fantasia que o sujeito entra em contato com o Outro da relação sexual, localizando-o no $\boldsymbol{a}$. É importante sublinhar que esta é a única flecha que sai do campo masculino. Veremos, mais adiante, as conseqüências dessa forma "masculina" de localizar o Outro sexo.

Entendemos que, se o homem toma a inscrição fálica como regra, é porque há um que se posiciona como exceção, portanto a função fálica encontra seu limite na existência de um ser que escapa à castração. Essa exceção opera o efeito de abarcar todos os homens, sob a égide da castração, em um conjunto. Miller (2003) ensina que o um, marcado na lógica da sexuação masculina, permite agrupar um todo pelo seu traço comum: todo da equipe, todo do exército, todo homogêneo no que diz respeito à identificação com o traço.

Do outro lado do Um está o Outro, ou seja, do lado da identidade está a alteridade, a diferença em sua radicalidade. Lacan, em suas Diretrizes para um Congresso sobre Sexualidade Feminina (1960/1998), aponta que uma mulher é Outra até para si mesma. O ser feminino, portanto, é suposto encarnar a diferença, inclusive consigo mesmo. A consequência disso é uma vacuidade essencial e a atribuição de receber, somente a partir da fantasia de um homem, uma identidade com alguma consistência. 
Lacan adjetivou a lógica fálica de para todos, uma vez que o falo, como significante redutível de um traço, permite agrupar elementos em função desse traço que vale para todos. Na outra lógica, ao contrário, o falo não conta, portanto não se tem um traço para formar conjunto; cada elemento submetido a essa lógica é ímpar. Em função disso, ele adjetivou-a como não-toda, situando nela o objeto $a$ de gozo e o enigma do Outro $(\not X)$, vivido especialmente pelo corpo como alteridade. (CALDAS, 2009)

Do lado da posição feminina, não há ninguém que não esteja submetido à castração. Portanto, se não há exceção, consequentemente, não há regra. Na lógica fálica do grupo fechado, a mulher, diferentemente do homem, não participa de uma regra, desse conjunto fechado que o falo delimita, a não ser que se localize do lado da posição masculina, identificando-se com a regra "para todos" que o axioma "para todo $x, \Phi \mathrm{x}$ " abarca. Do lado da inscrição feminina dos seres falantes, não há nenhuma universalidade, não há conjunto fechado. Se não há mulher que não esteja submetida à castração, não há exceção à regra. Resta, então, às mulheres localizarem-se divididas perante a castração, e essa divisão exerce uma determinação da identidade e do gozo feminino. As mulheres estão, em parte, submetidas ao gozo fálico e, em parte, a um gozo suplementar do qual nada sabem (LACAN, 1972-1973/1985). São, nomeadamente, não-todas.

Desde os primeiros escritos lacanianos sobre o feminino (1956) a mulher é localizada na fronteira entre um lugar de ausência e outro de pura sensibilidade. São localizadas a partir de um posicionamento limítrofe, que as cinde e as determina como não-todas fálicas. Porém, transitar no campo do feminino tem seu preço, pois a baliza fálica que atua no gozo presente do lado masculino, chamado gozo fálico, não tem efeito no domínio do feminino. A consequência é uma modalidade de gozo sem fronteiras. "Quando digo que a mulher é não-toda, e que é por isso que não posso dizer $a$ mulher, é precisamente porque ponho em questão um gozo que, em vista de tudo que serve na função $\Phi x$, é da ordem do infinito." (LACAN, 1972-1973/1985)

Os termos localizados abaixo das fórmulas lógicas no lado mulher são o $\boldsymbol{a}$, o $\mathbb{X}$ e o $\mathrm{S} \not \mathcal{X}$. Lacan ensina que o $\mathbb{X}$ é a única forma de grafia para "A mulher": " $A$ mulher, isto só se pode escrever barrando-se o A." (LACAN, 1972-1973/1985). Se o significante que designa a mulher não se faz presente, senão barrado, e se o comparamos com o $\Phi$ do lado masculino, podemos entender melhor o que está em jogo no que diz respeito à articulação entre o significante e a sexuação. No lado masculino, há um significante único que possibilita alguma designação fálica. Já no lado feminino, não há este significante, resultando em uma falta de significação e uma impossibilidade de identificação ou designação mínima.

A mulher, então, se duplica. As flechas que saem do $\mathbb{X}$ direcionam-se para dois elementos: no campo masculino para o $\Phi$ e no campo feminino para o $S(\mathbb{X})$. A mulher então tem relação com o $\mathrm{S}(\mathbb{X})$ no que diz respeito à falta de designação do Outro sexo na bateria significante dos seres falantes. Mas, por outro lado, dirige-se ao $\Phi$. Essa duplicação de flechas implica a natureza "não-toda" que designa a mulher. Sua ligação com o $\Phi$ a lança para uma articulação mínima com o falo, possibilitando a uma mulher também alcançar o gozo fálico e ficar, assim, regida - mesmo que não-toda - como o homem a uma ordem 
simbólica. Mas a outra flecha nos demonstra que uma mulher também permanecerá sob a égide de algo de que não há nomeação e que ela apenas experimenta: o gozo Outro.

Uma vez que é uma posição eleita de modalidade de gozo, sustentamos, então, que, na análise (espaço privilegiado de fala), o discurso das mulheres é marcado por uma condição outra que não comparece no discurso dos homens: a familiaridade com o $\mathrm{S}(\mathbb{X})$. A análise das mulheres apresenta certa particularidade que se explica pela peculiaridade de suas feminilidades. As mulheres são um pouco loucas, porque se referem a um duplo parâmetro: falo $(\Phi)$ e furo (S ( $\not X)$ ). Deparam-se com a castração e também com a falta de significante no campo do Outro. (LACAN, 1972-1973/1985) Isso se reflete em todas as escolhas de vínculos amorosos, sejam eles de amizade, eróticos ou até mesmo transferenciais.

\section{Amor e Devastarã̃ ${ }^{0}$ : a Parceria-sintoma}

Uma jovem analisanda diz, quando se refere ao laço que mantém com o homem amado, "sem ele, sinto como se perdesse um pedaço de mim. Finalmente entendo o que o Chico (Buarque) quis dizer quando escreveu 'ó, pedaço arrancado de mim"”. Outra analisanda é categórica quando afirma: "Tudo pode estar uma porcaria, mas se ele estiver comigo eu consigo enfrentar." Uma terceira, em um momento de sua associação-livre diz: "Preciso de um parceiro, preciso me sentir casada, senão pra quê que serve isso tudo?" (sic) Diante dessas falas tão repetidas nos settings analíticos, Miller ensina que “(...) o falasser feminino, na análise tem, em primeiro lugar, de resolver a questão do amor, e isso é a erotomania" (MILLER, 1998).

Lacan assinala, ainda em 1960, que "se a posição do sexo difere quanto ao objeto, é por toda a distância que separa a forma fetichista da forma erotomaníaca do amor" (LACAN, 1960/1998). Raciocínio que ecoa a premissa freudiana defendida no texto "Narcisismo" de 1914. Freud faz, então, uma diferenciação entre homens e mulheres, no que toca às duas escolhas de objeto amoroso e diz que para o homem é característica a escolha que é feita por uma veiculação sustentável, ou seja, aquela que é feita apoiada nas primeiras satisfações sexuais autoeróticas, que são vividas atreladas às funções vitais de autoconservação, e que elegem as pessoas envolvidas com o cuidado da criança como objeto. Já para a mulher,

(...) especialmente nos casos em que (...) venha a crescer bela, produzir-se-á uma auto-suficiência que a compensará pela atrofia de sua liberdade de escolha objetal imposta pela sociedade. Em rigor, é só a si mesmas que essas mulheres amam com intensidade comparável à do homem que as ama. Elas não têm necessidade de amar, mas de ser amadas, e estão dispostas a aceitar o homem que preencher essa condição. (FREUD, 1916/2004, vol. I)

No que concerne a cada um dos seres sexuados, do lado do homem, pela ligação entre $\$$ e $\boldsymbol{a}$, o Outro não é possível de ser relacionado como tal e resta a ele a designação de objeto $\boldsymbol{a}$. Este objeto toma forma de fetiche. Ou seja, por tentar alcançar a complementaridade do seu sexo, o Outro do seu sexo, acaba por buscar o mesmo objeto nos diferentes suportes que se apresentam: o objeto $a$ (MILLER, 2003). Para o homem a relação com uma mulher 
está, portanto, balizada pela fantasia, onde o outro só vale como "objeto a", objeto causa de desejo. Frente à inexistência da relação sexual, a mulher torna-se, então, o suporte do que há de semblante no laço entre um homem e uma mulher.

Do lado oposto, o feminino, há a erotomania e o objeto é suporte do amor. O que se pode deduzir dessas duas modalidades de relação de objeto é que, no homem, o desejo passa pelo gozo. Já na mulher, seu caminho é pelo amor. A diferença está na estrutura mesma que marca ambas as posições: no fetiche, a causa do desejo se localiza no mais-de-gozar do objeto $a$; na erotomania, o amor vai além e se relaciona ao $\mathbb{X}$. Sabemos que a face erotomaníaca do amor é tributária, tanto da modalidade feminina de gozo, quanto do laço pré-edipiano existente entre uma mulher e o Outro primordial. A psicanálise também ensina que, quando uma mulher escolhe um parceiro, este será herdeiro do vínculo que esta mantinha ou mantém com a mãe.

Miller (1998) afirma que, para amar é preciso falar. Uma vez que amar é dar o que não se tem, quando falamos oferecemos ao outro nossa falta-a-ser, a natureza barrada de todo sujeito que habita a linguagem. É quando faltam as palavras certas que um amante oferece as mais variadas palavras e provas de amor. Mas o homem, pela especificidade de sua posição, pode gozar sem palavras e sem amor, por mais que esse gozo seja apenas uma cota, circunscrita e contabilizável. Para uma mulher, sua modalidade de gozo exige que o parceiro eleito a ame e dê provas desse amor, ou seja, que a ame e fale sobre isso. Nos enlaces eróticos femininos, gozo e amor estão costurados em um movimento único e esse caráter imprime na sexualidade feminina um movimento radical. Para que uma mulher ame é preciso que o parceiro fale. Ao falar, o que está em jogo é a falta-a-ser do parceiro, ou seja, é uma demanda de amor que incide sobre o ser do parceiro. Mas, em última análise, esse movimento desnuda sua modalidade erotomaníca: que o Outro a ame (MILLLER, 1998). E para que o Outro a ame, não há que se ter pudores e avarezas:

\footnotetext{
Assim, o universal do que elas desejam é a loucura: todas as mulheres são loucas, como se diz. É por isso mesmo que são não-todas, isto é, não loucas-detodo, mas antes conciliadoras, a ponto de não haver limites para as concessões que cada uma delas faz a um homem: seu corpo, sua alma, seus bens. (LACAN, 1974/2003).
}

Lacan afirma, ainda, que as mulheres são loucas porque tem como parceiro o $\mathbb{X}$. Pela particularidade da demanda de amor que uma mulher direciona ao parceiro, marcada pela estrutura do não-todo e, portanto infinita, tal demanda retorna à mulher sob forma de devastação.

[...] A demanda de amor comporta, em si mesma, um caráter absoluto e uma visada ao infinito, que é manifestada pelo fato de que o Todo não está formado, o Todo não faz um, e isso se abre para o infinito, além de tudo o que se pode trocar de material, tudo o que se pode oferecer como prova. É uma demanda que incide sobre o ser do parceiro, e é isso que desnuda sua forma erotomaníaca - que o outro me ame (MILLER, 1998) 
Essa demanda infinita e devastadora pode ser para o melhor ou para o pior, avisa-nos Miller (1998). A devastação (ravage) tem, em si, o ravir de ravissement, ou seja, o deslumbramento. O laço devastador pode também conduzir a um estado de deslumbramento extremo, de captura, de rapto por uma força pulsional avassaladora. A mulher paga o preço cobrado pela economia de seu gozo devastador, por mais que isso esbarre em seu aniquilamento como sujeito. Ante esse gozo, do qual nada pode ser dito, e da falta de um significante que defina o que é uma mulher, a devastação, então, marcará presença, tanto no relacionamento entre mãe e filha, quanto nas parcerias amorosas, pois ambas possuem como ponto em comum a demanda infinita de amor.

De qualquer forma a devastação implica em dificuldades do sujeito nas relações de troca, em colocar o corpo na troca amorosa, no relacionamento sexual e na maternidade. Uma mãe deverá se separar dos objetos de seu corpo em sua relação com a filha. Se essa transmissão não ocorre, a devastação será a conseqüência desse deslumbramento narcísico que busca mais o amor desenfreado do que o desejo (DRUMMOND, 2010).

Para uma mulher, amor e devastação possuem estreito parentesco porque ambos estão sob o registro do sem limite e da falta de significante no Outro. Entende-se, portanto, a devastação, como "o retorno, ao falasser feminino, do infinito da demanda de amor, em função do não-todo que a caracteriza como excedente a função fálica" (ALVARENGA, 2003). Diante desse gozo, fora da lógica fálica e da falta de um significante que defina o que é uma mulher, a devastação se apresenta como uma modalidade no vínculo entre uma mulher e sua mãe e, por isso, passível de atuar nas parcerias amorosas e em todos outros enlaces, inclusive no amor de transferência. Na clínica com mulheres, a questão da devastação é sempre atual e o testemunho de suas conseqüências funestas aponta sempre para o enlace de um gozo mortífero, ligado à pulsão de morte, que tem a capacidade de aniquilar qualquer tipo de ligação erótica baseada na fantasia, ou seja, na articulação entre um sujeito e seus objetos parciais.

Uma analisanda conta sobre o laço angustiante e gozante que mantém com o noivo:

Às vezes eu provoco tanto ele que ele me bate. Nesse momento eu me sinto um lixo. Aí choro muito. Ele fica com pena e me consola. Então eu digo pra ele as piores coisas, as piores mesmo. E mesmo assim ele fica comigo. É quando eu sei que ele me ama. Aí eu sinto uma coisa muito boa, uma certeza que ficaremos juntos pra sempre (sic).

Ela acentua seu semblante de objeto de ódio e se faz desejar. A chave deste enlace masoquista é a erotomania, ou seja, não importa apanhar, o que importa é que ele bata na mulher que ama, que esta mulher seja seu objeto de amor. Essa erotomania que marca o que é específico do feminino se faz presente na vida de uma mulher em todos os enlaces amorosos que fizer.

Sabe-se que para uma mulher a causa do desejo perpassa pelo amor e pelo sua ligação ao $\mathrm{S}(\not{X})$. Tal modalidade de amor que vai ao infinito é uma das peculiaridades do enlace 
devastador entre mãe e filha. A literatura psicanalítica refere-se a isso como demanda ao infinito pela falta de balizamento fálico e aponta a causa na especificidade da modalidade de gozo que experimentam ambas nesse laço.

No vínculo entre uma mulher e sua mãe, é a impossibilidade de resposta à demanda de amor, potencialmente infinita, que retorna àquela que demanda, "precisamente sob a forma da devastação" (MILLER, 1998). O campo do Outro é tão opaco que à menina só cabe a re-petição, enviar novamente o pedido de amor, e mais uma vez, até o infinito. "A devastação é a outra face do amor, é o retorno da demanda de amor, o que quer dizer que é como o sintoma, exceto que tem um índice de infinito.” (ibid.)

Certa analisanda relata uma repetição no laço que possui com sua mãe: de tempos em tempos, rompe com ela e se muda de casa, o que dura um curto período de tempo e culmina na súplica da filha para voltar ao lar da mãe. À súplica, segue um período de relativa paz, no qual a analisanda se submete totalmente aos caprichos da mãe. A mulher devastada, arrebatada pelo gozo Outro presente em tal laço funesto, não vê outra estratégia a não ser apostar o excesso de seu gozo em vínculos que repetem a catástrofe da demanda infinita de amor. Vínculos que, ao contrário de Eros e dos liames que a amarração fálica promove, se eternizam na pulsão de morte.

Cada mulher, então, deve encontrar soluções particulares para alojar os excessos típicos da modalidade de gozo feminino em seu ser. A análise pode ser uma grande aliada das mulheres, pois ao acolher o que é da ordem do real de seus gozos, estabelece um campo, onde algo desse furo tão presente na condição feminina, possa advir e circunscrever o excesso que o feminino carrega.

Finalizamos reiterando nosso argumento que afirma: investigar a questão da feminilidade para a psicanálise, o envolvimento da mulher com sua mãe e as especificidades deste enlace podem permitir avanços importantíssimos em relação às questões que sempre comparecem à clínica. Nesse espaço de experiência psicanalítica, pesquisar sobre a feminilidade e mais especificamente sobre o vínculo entre mãe e filha é imperativo, pois sempre traz muitas contribuições para a clínica da psicanálise. Um olhar investigativo sobre os elementos em jogo nessa relação, tão peculiar, faz-se importantíssimo para o entendimento de certas questões levantadas na clínica das mulheres. Estudar o envolvimento da menina com a mãe, com seu corpo, desejo e gozo específicos permite avanços importantes no conhecimento do campo da especificidade feminina, que possibilita sempre novas construções teóricas. Mas, acima de tudo, nos auxilia em nossa clínica, porque permite o incremento de uma escuta mais atenta a nós mesmos e também aos analistas que se possam deparar com esta questão. Pois, por constituição e pela modalidade de amor que a elas pertence, as mulheres sempre serão um pouco devastadas e um pouco devastadoras. 


\section{Referências}

ALVARENGA, E. "Devastação na psicose." In: Clique - O sexo e seus furos. páginas 44-49. Revista dos Institutos Brasileiros de Psicanálise do Campo Freudiano. Rio de Janeiro, 2003.

BROUSSE, M-H. "Uma dificuldade na análise das mulheres: a devastação da relação com a mãe.” Revista Latusa: A política do medo e o dizer do psicanalista ₹v.9, 2004, p.203-218. Rio de Janeiro.

CALDAS, H. "Cartas de amor semblante". Revista Latusa: Sintoma e Semblantes na Vida e na Análise. v. 14, 2009, p. 53-64. Rio de Janeiro, 2009.

DRUMMOND, C. "A Devastação", endereço: http://www.ebp.org.br/biblioteca/pdf biblioteca/Cristina_Drummond_A_devastacao.pdf, Acesso em 01/07/2010.

FREUD, S. “À Guisa de Introdução ao Narcisismo” [1914]. In Escritos sobre a psicologia do inconsciente, páginas 95-119. Rio de Janeiro: Imago, 2004.

LACAN, J. "Diretrizes para um congresso sobre a sexualidade feminina" [1958]. In Escritos, Rio de Janeiro: Jorge Zahar Editor, 1998, páginas 734-745.

Zahar Editor, 2003.

"O Aturdido". In Outros Escritos, páginas 448-497. Rio de Janeiro: Jorge . “Televisão". In Outros Escritos, páginas 508-543. Rio de Janeiro: Jorge Zahar Editor, 2003 1985.

. "O Seminário". In Outros Escritos. Rio de Janeiro: Jorge Zahar Editor,

MILLER, J.A. "A criança entre a mulher e a mãe”. Revista Opção Lacaniana _Rio de Janeiro, v. 2, 1998, p. 7-12. Rio de Janeiro

. "Uma partilha sexual" Clique: Revista dos Institutos Brasileiros de Psicanálise do Campo Freudiano. - O sexo e seus furos. v. 2, p. 13-29. Rio de Janeiro, 2003.

MURTA, C. "O amor entre filosofia e psicanálise". in Revista do Departamento de Psicologia da UFF. Niteroi: v. 18, n. 1, p. 57-70, 2006.

ROUDINESCO, Elizabeth. \& PLON, Michel. Dicionário de Psicanálise. Rio de Janeiro: Jorge Zahar Ed., 1998.

SOLER, Collete. O que Lacan dizia das mulheres. Rio de Janeiro: Jorge Zahar Ed., 2005 . 